DOI: 10.20472/IAC.2018.041.010

\author{
GRACE CHANG \\ Young Lives, University of Oxford, United Kingdom \\ MARTA FAVARA \\ Young Lives, University of Oxford, United Kingdom \\ RAFAEL NOVELLA \\ Inter-American Development Bank, United States
}

\title{
THE ORIGINS OF COGNITIVE SKILLS AND PERSONALITY: THE EFFECT OF IN-UTERO CLIMATE SHOCKS ON CHILDREN'S FUTURE LIFE OUTCOMES
}

\begin{abstract}
:
A large literature stemming from the Fetal Origins Hypothesis (Barker, 1990) discuss the importance on the in-utero period as critical in shaping a person's future development. More recently, economists have further tested this theory by investigating how fetal experiences are related to a variety of future economic outcomes. This paper investigates the effect of in utero exposure to rainfall shocks in India on future accumulation of human capital. For this analysis, we match the Young Lives data, following a cohort of children born between the years 2000 and 2001 up to age 15 , and climate data from the University of Delaware. We estimate the impact of in utero exposure to rainfall shocks on children's cognitive (mathematics and vocabulary) and non-cognitive skills (core self-evaluation) at age 15 by using a community fixed effects model to control for any unobservable correlates of weather patterns and local levels of human capital formation. Furthermore, we investigate the effects of rainfall deviations that occur during the first, second and/or third trimesters of pregnancy. We argue that timing of the exposure to shocks might be important to cognitive and non-cognitive skills formation considering that the critical window for the fetus' brain development is between the 24 th and 42 nd week of gestation.

Our results show significant and negative effects of exposure to anomalous rainfall deviations from the historical mean on children's cognitive scores at age 15, particularly when affected by a negative one standard deviation shock. We also find a significant and negative impact on children's core self-evaluation from a two standard deviation shock. The second trimester appears to be the critical window of exposure on cognitive outcomes, while the first trimester seems to be important to the non-cognitive outcome.

Hence, our results point to the persistent effects of exposure to rainfall deviations during pregnancy on future human capital development. This highlights the need for policies to think more about individual life-course and intergenerational mobility, where focusing on mothers can help children's development outcomes in the future.
\end{abstract}

\section{Keywords:}

human capital development, fetal origins hypothesis, non-cognitive skills, cognitive skills, climate 